\title{
Effect of Adding Silicon Carbide and Titanium Carbide Nanoparticles on the Performance of the Cement Pastes
}

\author{
Aamir Mahawish ${ }^{1 *}$, Sarmed Imad Ibrahim², Ali Hussein Jawad ${ }^{2}$ and Ferhad Mohamed Othman ${ }^{2}$ \\ ${ }^{1}$ Department of Highway and Transportation Engineering, University of Al-Mustansiriyah, Iraq \\ ${ }^{2}$ Department of Materials Engineering, University of Technology, Baghdad, 00964, Iraq
}

\begin{abstract}
The nanoparticle is used into cement pastes to improve its engineering properties. In this paper, silicon carbide (SiC) and titanium carbide (TiC) nanoparticles with a particle size $(20 \mathrm{~nm})$ were added at different percentages $1 \%$, $2 \%, 3 \%, 4 \%, 5 \%$ and $6 \%$ ) to cement pastes. The cement pastes were tested for mechanical and physical properties at different curing ages $(7,14,21$, and 28 days). The results of mechanical and physical tests showed a significant improvement with all mixtures of nanoparticles, and the maximum values of the mechanical and physical tests were associated with the cement paste samples with $5 \% \mathrm{TiC}$ at curing time 28 days. SEM results showed the control samples of cement paste had needle shapes to structure $\mathrm{Ca}(\mathrm{OH}) 2$ with the of large pores. However, adding of nanoparticles resulted in absence of needle shape structures, pore spaces and produced a homogeneous structure of compounds (C-SH).
\end{abstract}

Keywords: Nano particles; Cement paste; Strength; Scanning electron microscopy

\section{Introduction}

In the recent decade, the nano-materials have shown a great development since its impact on construction materials [1,2]. The use of nanotechnology products especially nano-powder has increased. Nano-powder can improve the mechanical properties of cement pastes due to accelerating the hydration, the formation of small-sized crystals (such as $\mathrm{Ca}(\mathrm{OH})$ and Atomic Force Microscopy (AFM)) and the uniform clusters of C-S-H [1-5]. Nano-powder can also improve the durability of cement-based composites due to filling very small pores. The size of nano-powder is important as it has to be compatible with the pore structures of cement [1-5]. Mehta stated the cement particle size is important for its reaction with water as more fine cement, the more rapid reactions with water [6]. Many researches have been carried out experimental works over the recent years with the view to understand the effect of fine and ultra-fine materials (nanoparticles) on the cement properties [2,7-9].

Nanoparticles are used either to replace part of cement, inducing ecologic profile concrete [7] or as an admixture in the cement pastes $[8,9]$. In both cases, the addition of nano-scale particles improves the performance of cement; for instance, an improvement of rheological properties has been observed in the fresh cement mixtures [10], whereas, the compressive strength was increased in the hardened state [11]. The nano-scale observations revealed the nano-crystallized structure of $\mathrm{C}-\mathrm{S}-\mathrm{H}$ cement phase $[12,13]$, and the nanoparticles work as a nucleation site for the cement phase promoting a cement hydration $[14,15]$. The most common nanoparticles in cement products are $\mathrm{SiO}_{2}$, $\mathrm{TiO}_{2}, \mathrm{Al}_{2} \mathrm{O}_{3}$ and carbon nanotubes [16-18]. Nano- $\mathrm{SiO}_{2}$ has played a significant role according to Sobolev and Gutiérrez to modify cement mixtures [19].

Nano- $\mathrm{SiO}_{2}$ particles lead to the chemical reaction between $\mathrm{SiO}_{2}$ and $\mathrm{Ca}(\mathrm{OH})_{2}$ which is released during cement hydration. The previous mechanism can cause to reduce of $\mathrm{SiO}_{2}$ grain size contributing to increasing the strength and reduce permeability. "The great reactivity of nanoparticles is attributed to a high purity and a specific area in relation to its volume" [20]. The effect of nanoparticles sizes has been studied by numerous studies as the nanoparticle cement mixtures tend to increase the demanding for water for the same workability $[9,20]$. In addition, nanoparticles tend to agglomerate, which can be avoided by using dispersing additives or applying different techniques during mixing $[15,16]$. Li recorded a dense, homogeneous structure in nanoparticles modified mortars and a compact transition zone between aggregates and paste [8]. Sobolev et al. [20] reported that the nano-modified mixtures can reduce the initial strength with the curing age. Li tested cement products with fly ash and concluded that the pozzolanic reaction of fly ash is improved by adding nano- $\mathrm{SiO}_{2}$ to the mixture [8].

The present study focuses on the structural changes of cement pastes when adding ( $\mathrm{SiC}$ and $\mathrm{TiC}$ ) nanoparticles as admixtures in different percentages. Scanning Electron Microscopy and Energy Dispersive Spectroscopy have been employed in identifying the structural changes in nanoparticles modified pastes. The mechanical and physical tests have been conducted at different curing ages.

\section{Materials and Methods}

\section{Materials}

Ordinary Portland cement was used throughout the current study. Nanoparticles powder was supplied by Nanostructured and Amorphous Material Inc., USA. The chemical compositions of cement are presented in Table 1, and the properties of nanoparticles ( $\mathrm{SiC}$ and $\mathrm{TiC})$ powder are given in Table 2.

\section{Sample preparation}

A Portland cement was replaced with nanoparticles with (1\%, $2 \%, 3 \%, 4 \%, 5 \%$ and $6 \%$ ) by weight of cement. The nanoparticles were mixed with cement in a dry condition, and the dry mixtures were sieved several times for a proper dispersion of the nanoparticles. The water-binder ratio $(\mathrm{W} / \mathrm{B})$ used was 0.45 . Cement paste cubes of 50 $\mathrm{mm}$ size were cast and vibrated in a table vibrator. The specimens were

*Corresponding author: Aamir Mahawish, Department of Highway and Transportation Engineering, University of Al-Mustansiriyah, Iraq, Tel: 411226049; E-mail: aamir.mahawish@monash.edu

Received June 09, 2016; Accepted July 31, 2017; Published August 06, 2017

Citation: Mahawish A, Ibrahim SI, Jawad AH, Othman FM (2017) Effect of Adding Silicon Carbide and Titanium Carbide Nanoparticles on the Performance of the Cement Pastes. J Civil Environ Eng 7: 277. doi: 10.4172/2165-784X.1000277

Copyright: (c) 2017 Mahawish A, et al. This is an open-access article distributed under the terms of the Creative Commons Attribution License, which permits unrestricted use, distribution, and reproduction in any medium, provided the original author and source are credited. 


\begin{tabular}{|c|c|}
\hline Oxides & Content (\%) \\
\hline $\mathrm{SiO}_{2}$ & 20.3 \\
\hline $\mathrm{Al}_{2} \mathrm{O}_{3}$ & 4.4 \\
\hline $\mathrm{Fe}_{2} \mathrm{O}_{3}$ & 2.6 \\
\hline $\mathrm{CaO}$ & 62.5 \\
\hline $\mathrm{MgO}$ & 2.5 \\
\hline $\mathrm{SO}_{3}$ & 2.1 \\
\hline $\mathrm{LOI}$ & 1 \\
\hline
\end{tabular}

Table 1: Chemical composition of cement.

\begin{tabular}{|c|c|c|c|c|c|}
\hline Constituents & Purity & $\begin{array}{c}\text { Average } \\
\text { particle size }\end{array}$ & $\begin{array}{c}\text { Specific } \\
\text { Surface area }\end{array}$ & Color & $\begin{array}{c}\text { TRUE } \\
\text { density }\end{array}$ \\
\hline Nano-SiC & $99.50 \%$ & $\leq 20 \mathrm{~nm}$ & $195 \mathrm{~m}^{2} / \mathrm{g}$ & Greyish white & $3.216 \mathrm{~g} / \mathrm{cm}^{3}$ \\
\hline Nano-TiC & $99.50 \%$ & $\leq 20 \mathrm{~nm}$ & $210 \mathrm{~m}^{2} / \mathrm{g}$ & Black & $4.93 \mathrm{~g} / \mathrm{cm}^{3}$ \\
\hline
\end{tabular}

Table 2: Properties of nanoparticles.

then demolded and cured in tap water until testing. Scanning Electron Microscopy and Energy Dispersive Spectroscopy of hydrated cubes were conducted on the samples taken from the specimen that induced the best mechanical and physical results.

\section{Test methods}

Compressive strength: The compressive strength test was determined by two testing machines:

1. Portable mechanical tester: The compressive strength test was determined according to ASTM C (780-002). The compressive strength of the specimen was calculated by dividing the maximum load carried by the specimen during the test by the average cross-sectional area of the specimen. The load was applied perpendicularly and continuously on the specimen by using hydraulic testing compression machine with a maximum load (15 ton).

2. Electrical digital compression tester (ELE International AccuTek 250): An electrical digital compression tester can provide a consistent testing on a wide range of specimens through a hydraulic pump and a digital readout system.

Splitting tensile strength: Splitting tensile test was performed according to ASTM C (496-04). The determination of the splitting tensile strength was done by conducting the splitting tensile test on the cylindrical specimens.

The cement paste specimens were placed horizontally between plates of the testing machine. In order to support the testing specimens, narrow strips of plywood were required to interpose between the specimens and the plates. The strips were usually a $3 \mathrm{~mm}$ thick and a $25 \mathrm{~mm}$ width as per ASTM C (496-04).

Flexural strength: The flexural strength tests were conducted on $40^{\star} 40^{\star} 160 \mathrm{~mm}$ prism specimens in conformity with ASTM C (348-02). The prism specimens were subjected to two-point loading. The flexural strength of the cement paste was tested at ages of $(7,14,21$, and 28 days). The average of three specimens was recorded for each testing age. Flexural strength was calculated by using the following equation:

$$
\mathrm{Sf}=0.0028 \mathrm{P}
$$

Where: Sf: Flexural strength (MPa), P: Total maximum load (N).

Water absorption: Water absorption tests were conducted on the control cement paste specimens and the cement paste modified with the nanoparticles. The test was carried out in accordance to ASTM C (642-1997). In the test procedure, the specimens were dried in an oven at $\left(100-110^{\circ} \mathrm{C}\right)$ for 24 hours, and then their masses were measured.
Next, the specimens were fully immersed in a water tank for 24 hours, then they were taken out. Their surfaces were dried with a cloth and finally their weights were measured again. The test was conducted on the specimens with different curing ages $(7,14,21$, and 28 days), and the percentage of water absorption was calculated from the following equation:

$$
\text { Water absorption }(\%)=(\mathrm{W} 2-\mathrm{W} 1) / \mathrm{W} 1 \times 100
$$

Where: W1: The average weight of dry sample (g), W2: The average weight of the wet sample (g).

Scanning Electron Microscopy (SEM) and Energy Dispersive X-Ray (EDX): The scanning electron microscope (SEM) is comparatively more useful in studies which investigate quantification of microstructural properties, such as micro-cracks, voids and to diagnose of the formed microstructural phases as studied by Shah in 2004. SEM is a powerful technique for analyzing the morphology of the prepared cement paste samples mixed with the nanoparticles and the control cement pastes. Scanning electron microscope (SEM) (Type TESCAN) was used in this study. The microstructure of the prepared samples was examined to determine the influence of adding the nanoparticles. Discs with a $20 \mathrm{~mm}$ thick were extracted using a diamond precision cutter from the samples that were moist cured for 28 days. The discs were dried in a vacuum oven at $50^{\circ} \mathrm{C}$ until a constant weight reached. The specimens were then impregnated with epoxy, polished and sputter coated. Scanning Electron Microscope (SEM) examinations were carried out in the secondary electron mode using an Apex Personal SEM. Energy dispersive X-ray was also used to identify the phases.

\section{Results and Discussion}

\section{Compressive strength}

The Compressive strength is the most important property of the concrete that is considered in the structural designs. The compressive strength results of the cement pastes with different nanoparticles ( $\mathrm{SiC}$ and $\mathrm{TiC})$ percentages $(1 \%, 2 \%, 3 \%, 4 \%, 5 \%$ and $6 \%)$ at a curing time $(7,14,21$ and 28 days) are presented in Figures 1-6, respectfully. It can be seen from Figures 1-6 that all the specimens of the cement pastes modified by the nanoparticles were higher compressive strength than the control cement paste specimens' at all curing periods.

It is also seen from Figures 1-6 that a comparison between the cement paste specimens reinforced by $\mathrm{SiC}$ and $\mathrm{TiC}$ is presented along with the control samples at various curing periods. It is clearly seen from these figures that the compressive strength of control specimens was

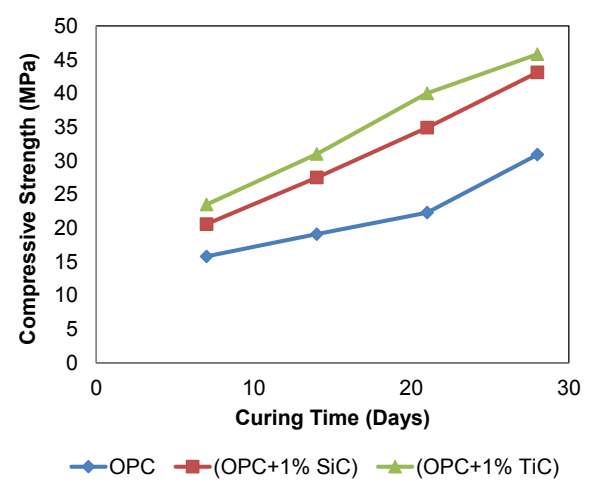

Figure 1: Effect of $(1 \% \mathrm{SiC})$ and $(1 \% \mathrm{TiC})$ nanoparticles on the compressive strength for the cement paste specimens at different curing time. 


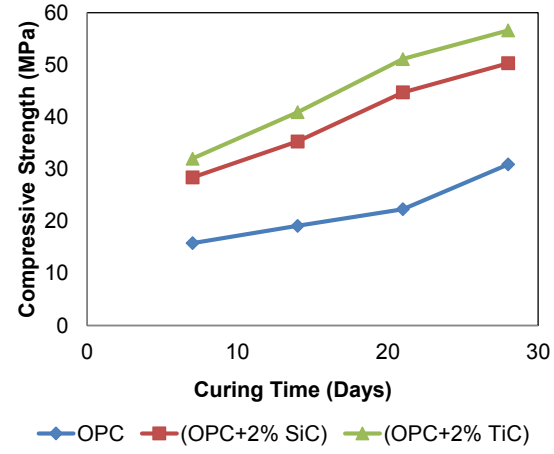

Figure 2: Effect of $(2 \% \mathrm{SiC})$ and $(2 \% \mathrm{TiC})$ nanoparticles on the compressive strength for the cement paste specimens at different curing time.

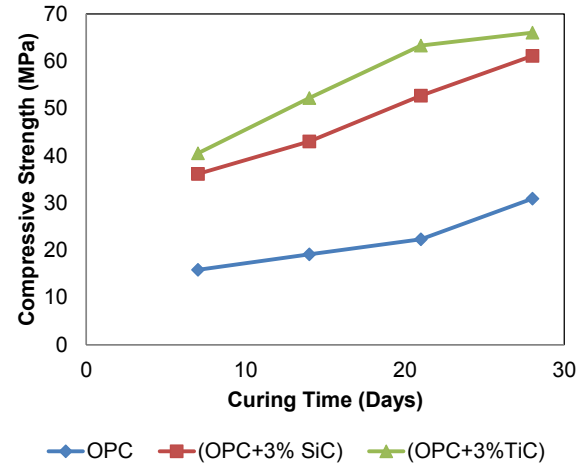

Figure 3: Effect of (3\% $\mathrm{SiC})$ and $(3 \% \mathrm{TiC})$ nanoparticles on the compressive strength for the cement paste specimens at different curing time.

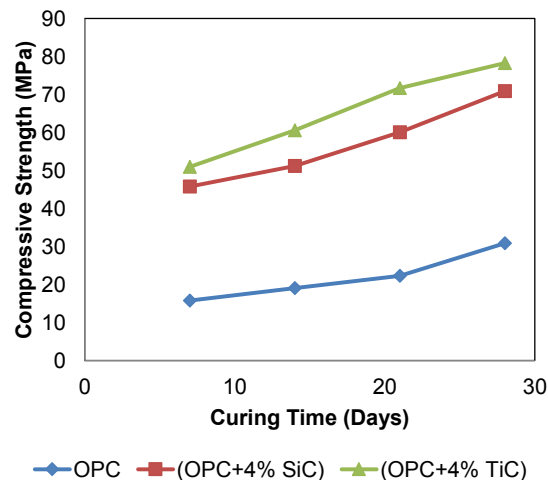

Figure 4: Effect of (4\% $\mathrm{SiC})$ and $(4 \% \mathrm{TiC})$ nanoparticles on the compressive strength for the cement paste specimens at different curing time.

lower than the cement paste samples reinforced by the nanoparticles. This is because "nanoparticles packed into the cement pastes pores can increase its resistance to compressive forces and the tiny nanoparticles size can be efficient to fill the void of cement paste mixtures" [21]. Another important factor to note is that the nanoparticles may promote the pozzolanic reactions [21].

The compressive strength of cement paste reinforced by (TiC) nanoparticles was greater than cement paste reinforced by $(\mathrm{SiC})$ nanoparticles in all testing conditions (i.e., percent of nanoparticles and curing periods) as shown in Figures 1-6. Also, these figures reveal

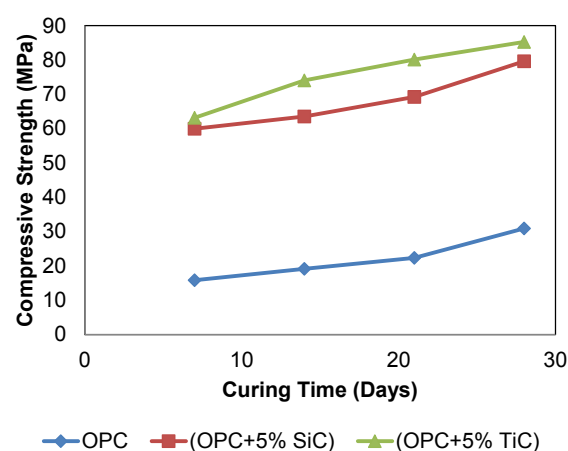

Figure 5: Effect of (5\% $\mathrm{SiC})$ and $(5 \% \mathrm{TiC})$ nanoparticles on the compressive strength for the cement paste specimens at different curing time.

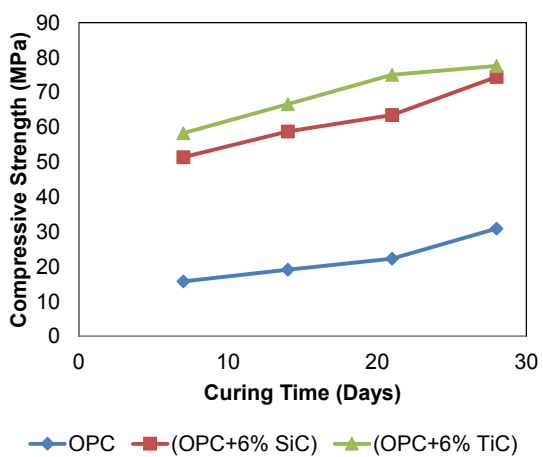

Figure 6: Effect of (6\% $\mathrm{SiC})$ and $(6 \% \mathrm{TiC})$ nanoparticles on the compressive strength for the cement paste specimens at different curing time.

that the maximum compressive strength of cement paste samples was achieved by adding $5 \% \mathrm{TiC}$ and $5 \% \mathrm{SiC}$ at curing time 28 days.

The effect of curing period on compressive strength for the control cement pastes samples and the cement pastes - nanoparticles mixtures is presented in Figures 1-6. The compressive strength increased with increasing the curing period for all cement paste mixtures. It can also be seen that the cement paste mixtures with $(\mathrm{TiC})$ nanoparticles had the highest strength at all curing periods, and the compressive strength of the cement paste increased with increasing the percentage of nanoparticles up to (5\%). The early effect of the nanoparticles may be due to its influence on accelerating the pozzolanic transformation of $\mathrm{C} 3 \mathrm{~S}, \mathrm{C} 2 \mathrm{~S}$ and $\mathrm{CH}$ into the $\mathrm{C}-\mathrm{S}-\mathrm{H}$ gel which was responsible for the strength improvements of the cement pastes. The cement pastes mixtures with (5\% TiC) nanoparticles (Figure 5) were the highest in gaining early strength at all curing periods due to it has small particles, which were superior in the filling the cement paste pores [22,23].

\section{Splitting tensile strength}

The tensile strength results of the cement pastes and the cement pastes with different nanoparticles percentages are presented in Figures 7-12. It is clearly observed in Figures 7-12 that the tensile strength increased with an increase in the nanoparticles percentages to reach an optimum value (Figure 11). The tensile strength of the cement paste prepared with different percentages of nanoparticles $(20 \mathrm{~nm}$ particle size) was higher than the tensile strength of the control cement pastes samples as presented in Figures 7-12. It can be clearly seen from these figures that the cement paste mixtures with $5 \% \mathrm{TiC}$ and $5 \% \mathrm{SiC}$ 


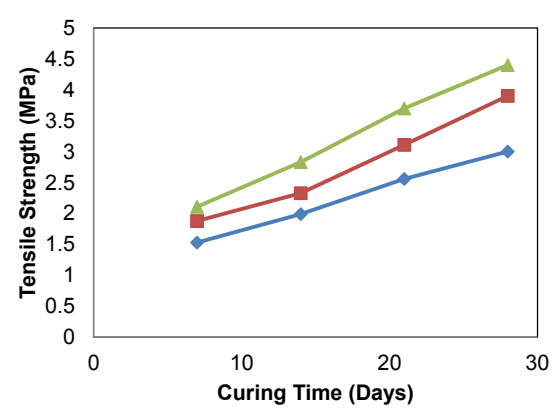

$\rightarrow-\mathrm{OPC} \rightarrow-(\mathrm{OPC}+1 \% \mathrm{SiC}) \rightarrow(\mathrm{OPC}+1 \% \mathrm{TiC})$

Figure 7: Effect of $(1 \% \mathrm{SiC})$ and $(1 \% \mathrm{TiC})$ nanoparticles on the tensile strength for the cement paste specimens at different curing time.

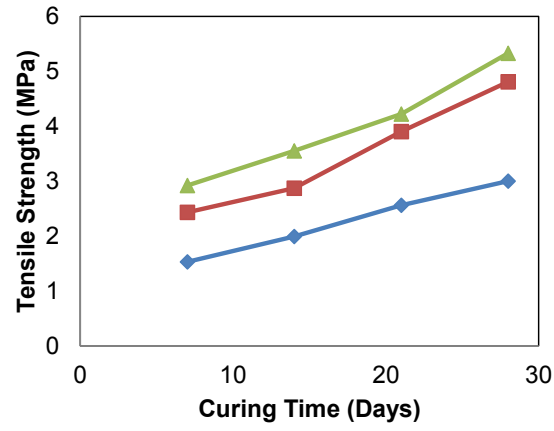

$\neg \mathrm{OPC}=(\mathrm{OPC}+2 \% \mathrm{SiC})-(\mathrm{OPC}+2 \% \mathrm{TiC})$

Figure 8: Effect of $(2 \% \mathrm{SiC})$ and $(2 \% \mathrm{TiC})$ nanoparticles on the tensile strength for the cement paste specimens at different curing time.

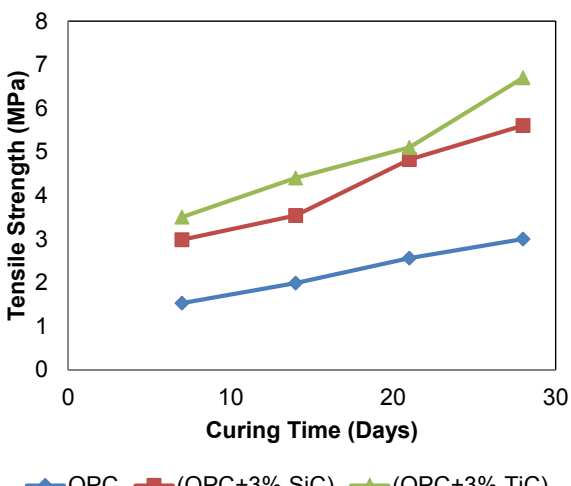

Figure 9: Effect of $(3 \% \mathrm{SiC})$ and $(3 \% \mathrm{TiC})$ nanoparticles on the tensile strength for the cement paste specimens at different curing time.

(Figure 11) showed a higher tensile strength than their counterparts prepared with low nanoparticles percentage at the curing age of 28 days. Another point to note from these figures is that adding $\mathrm{SiC}$ and $\mathrm{TiC}$ to cement paste increased the tensile strength of the specimens at inconsistent rates [8].

The effect of curing ages $(7,14,21$, and 28 days) on tensile strength of control mixtures, and the cement pastes with the different nanoparticles percentages $(1 \%, 2 \%, 3 \%, 4 \%, 5 \%$ and $6 \%)$ mixtures is presented in Figures 7-12. It can be seen from these figures that the tensile strength consistently increased with the increase in the curing

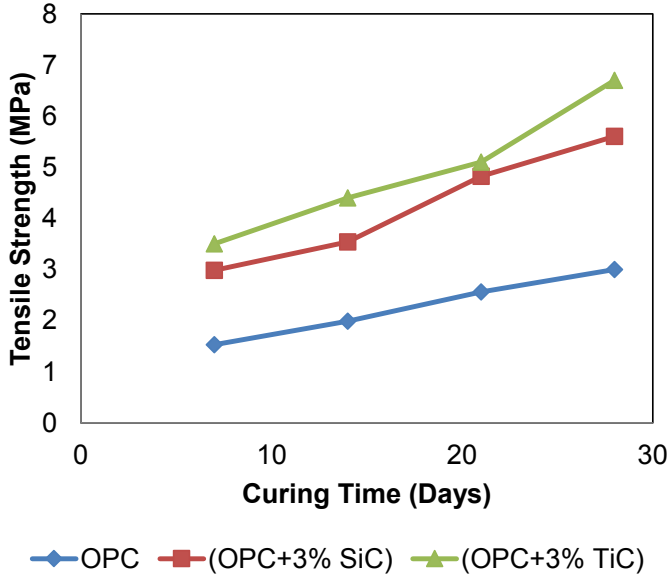

Figure 10: Effect of $(4 \% \mathrm{SiC})$ and $(4 \% \mathrm{TiC})$ nanoparticles on the tensile strength for the cement paste specimens at different curing time.

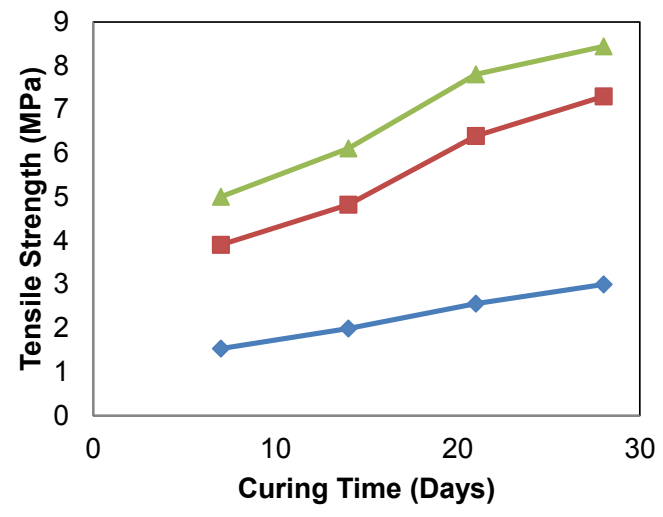

$\leadsto \mathrm{OPC}=-(\mathrm{OPC}+5 \% \mathrm{SiC})-(\mathrm{OPC}+5 \% \mathrm{TiC})$

Figure 11: Effect of $(5 \% \mathrm{SiC})$ and $(5 \% \mathrm{TiC})$ nanoparticles on the tensile strength for the cement paste specimens at different curing time.

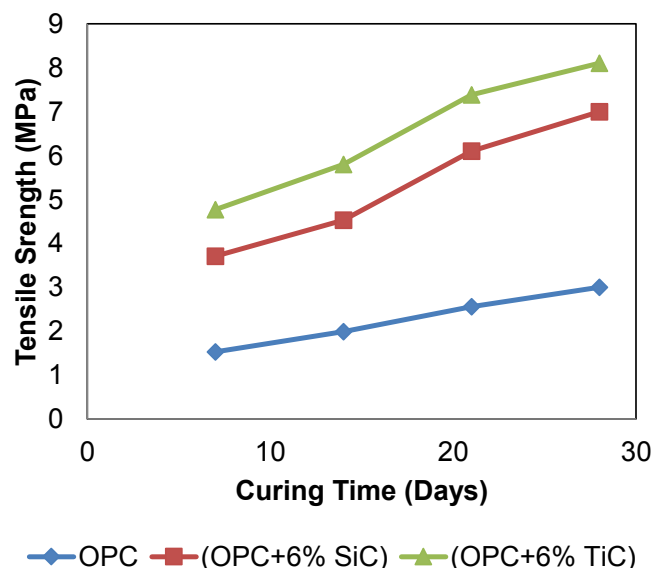

Figure 12: Effect of $(6 \% \mathrm{SiC})$ and $(6 \% \mathrm{TiC})$ nanoparticles on the tensile strength for the cement paste specimens at different curing time.

age for all cement paste mixtures. It can also be observed from these figures that the highest tensile strength was gained for cement paste mixtures with (TiC and $\mathrm{SiC}$ ) nanoparticles at the curing age of 28 
Citation: Mahawish A, Ibrahim SI, Jawad AH, Othman FM (2017) Effect of Adding Silicon Carbide and Titanium Carbide Nanoparticles on the Performance of the Cement Pastes. J Civil Environ Eng 7: 277. doi: 10.4172/2165-784X.1000277

days. It could be concluded that adding nanoparticles to cement paste mixtures increased its tensile strength. The reason for this may be related to the large surface area of nanoparticles which promote the pozzolanic reaction to form $\mathrm{C}-\mathrm{S}-\mathrm{H}$ gel which in turn gives the mixture its strength $[22,23]$.

\section{Flexural strength}

The results of the flexural strength of the control cement pastes and the cement paste samples modified by various percentages $(1 \%$, $2 \%, 3 \%, 4 \%, 5 \%$ and $6 \%$ ) of ( $\mathrm{SiC}$ and $\mathrm{TiC}$ ) nanoparticles at different curing time (7, 14, 21 and 28 days) are presented in Figures 13-18. It

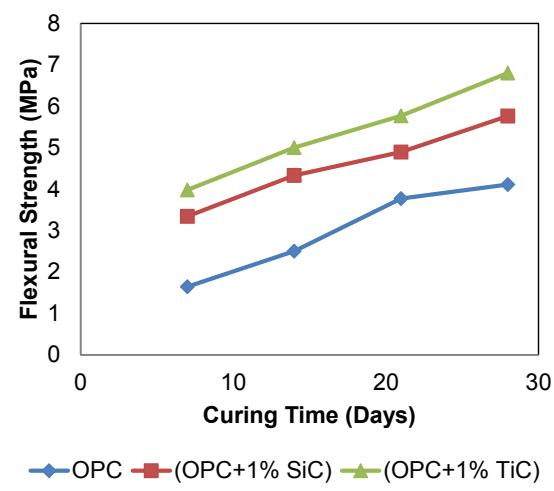

Figure 13: Effect of $(1 \% \mathrm{SiC})$ and $(1 \% \mathrm{TiC})$ nanoparticles on the flexural strength for the cement paste specimens at different curing time.

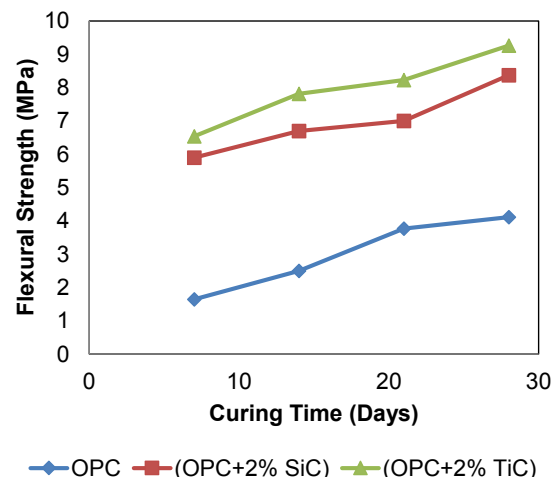

Figure 14: Effect of $(2 \% \mathrm{SiC})$ and $(2 \% \mathrm{TiC})$ nanoparticles on the flexural strength for the cement paste specimens at different curing time.

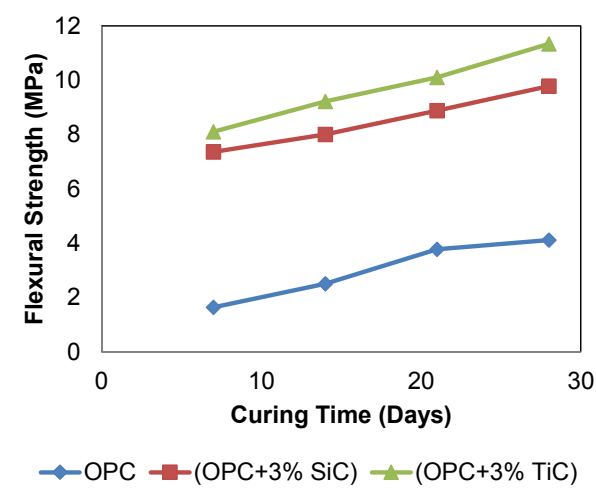

Figure 15: Effect of $(3 \% \mathrm{SiC})$ and $(3 \% \mathrm{TiC})$ nanoparticles on the flexural strength for the cement paste specimens at different curing time.

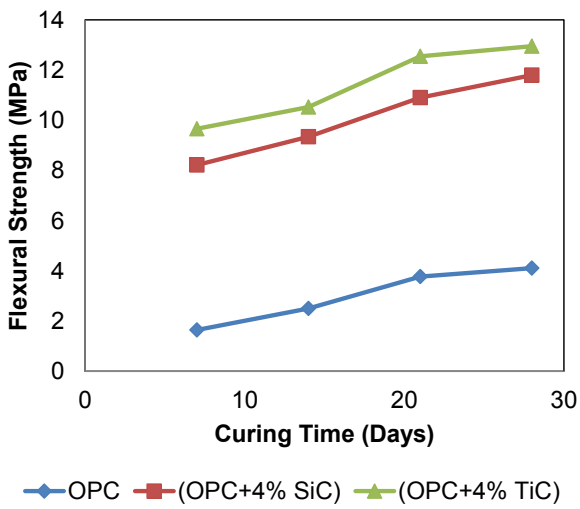

Figure 16: Effect of $(4 \% \mathrm{SiC})$ and $(4 \% \mathrm{TiC})$ nanoparticles on the flexural strength for the cement paste specimens at different curing time.

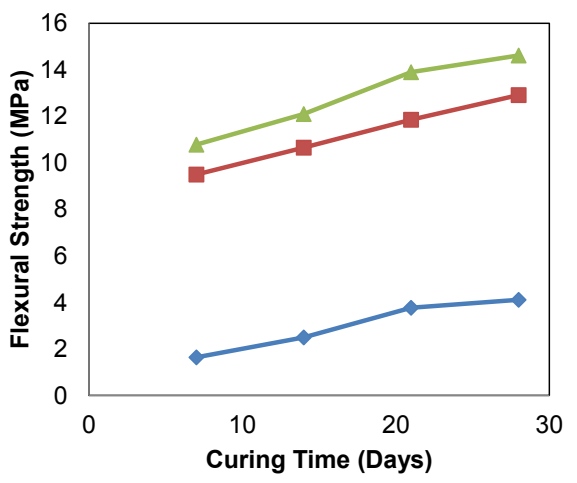

$\neg-\mathrm{OPC} \leftrightharpoons-(\mathrm{OPC}+5 \% \mathrm{SiC}) \leadsto(\mathrm{OPC}+5 \% \mathrm{TiC})$

Figure 17: Effect of $(5 \% \mathrm{SiC})$ and $(5 \% \mathrm{TiC})$ nanoparticles on the flexural strength for the cement paste specimens at different curing time.

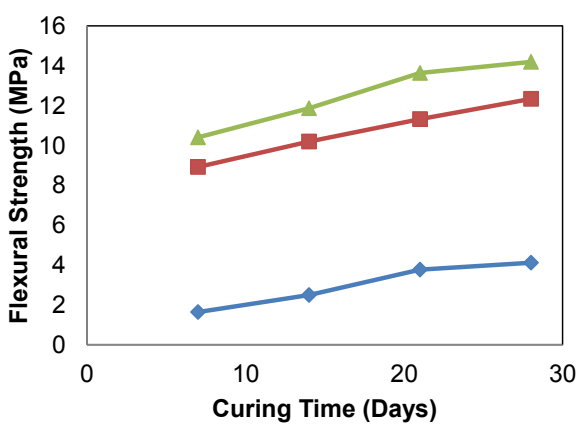

$\leadsto \mathrm{OPC}=(\mathrm{OPC}+6 \% \mathrm{SiC}) \rightarrow(\mathrm{OPC}+6 \% \mathrm{TiC})$

Figure 18: Effect of $(6 \% \mathrm{SiC})$ and $(6 \% \mathrm{TiC})$ nanoparticles on the flexural strength for the cement paste specimens at different curing time.

can be clearly seen from the figures that the flexural strength increased with increasing nanoparticles percentages and the curing time. This behaviour was attributed to the continuity of hydration process, which induced new hydration by products (calcium silicate hydrate (CSH)) within the cement paste $[24,25]$.

It is also observed that the maximum flexural strength could be achieved when using a combination of $5 \% \mathrm{TiC}$ and $5 \% \mathrm{SiC}$ nanoparticles (Figure 17) with the cement pastes at curing time 28 
days. The nanoparticles can lead to having a very dense structure, less porosity and reduce capillary voids of the cement pastes. This is because the nanoparticles can react with $\mathrm{CH}$ to induce $\mathrm{CSH}$, fill the voids the cement pastes $[24,25]$. The flexural strength of the cement pastes specimens increased with an increase the percentages of nanoparticles up to $(5 \%)$. The addition of $(5 \% \mathrm{TiC})$ and $(5 \% \mathrm{SiC})$ nanoparticles to the cement pastes specimens resulted in the higher flexural strength than the other experimental specimens.

However, it is interesting to note from the flexural strength results that a little reduction in the flexural strength was associated with adding $6 \%$ nanoparticles. This may be related to the fact that the quantity of $(\mathrm{TiC})$ and $(\mathrm{SiC})$ nanoparticles presented in the cement paste mixtures were higher than the required amount to combine with the liberated lime during the hydration process $[26,27]$ Thus, leading to the leaching out of excess silica and causing a reduction in strength It may also occur in the poor dispersion of nanoparticles, which cause weak zones [26,27].

\section{Water absorption}

The water absorption test was conducted in order to study the effect of mixing nanoparticles with the cement paste mixtures. Figures 19-24 show the water absorption test results of the control cement pastes mixtures and the cement paste mixtures modified by various ( $\mathrm{SiC}$ and $\mathrm{TiC}$ ) nanoparticles percentages $(1 \%, 2 \%, 3 \%, 4 \%, 5 \%$ and $6 \%$ ) respectively at different curing time $(7,14,21$ and 28 days). It is clearly seen from these figures that the water absorption for the modified cement pastes specimens was lower than the control cement pastes samples. These figures also reveal that the water absorption decreased

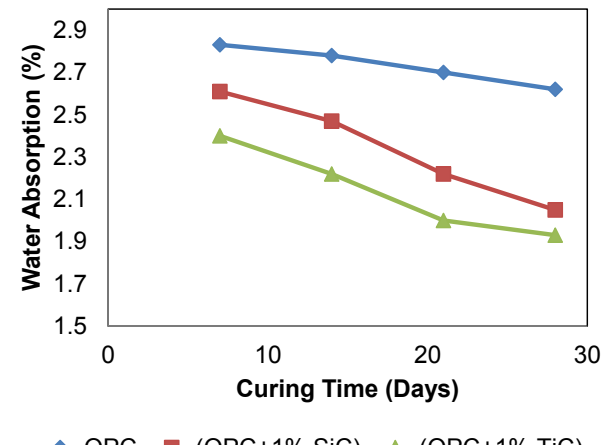

Figure 19: Effect of $(1 \% \mathrm{SiC})$ and $(1 \% \mathrm{TiC})$ nanoparticles on the water absorption for the cement paste specimens at different curing time.

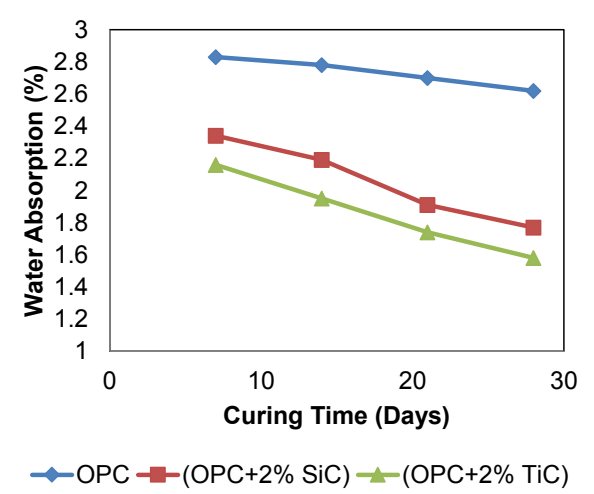

Figure 20: Effect of $(2 \% \mathrm{SiC})$ and $(2 \% \mathrm{TiC})$ nanoparticles on the water absorption for the cement paste specimens at different curing time.

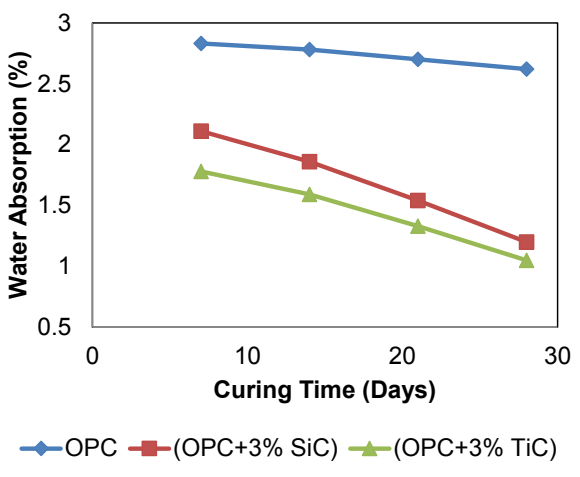

Figure 21: Effect of (3\% $\mathrm{SiC})$ and (3\% $\mathrm{TiC})$ nanoparticles on the water absorption for the cement paste specimens at different curing time.

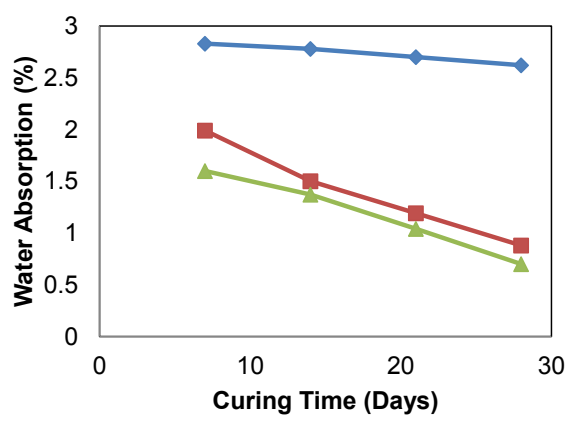

$\leadsto \mathrm{OPC}=-(\mathrm{OPC}+4 \% \mathrm{SiC})=(\mathrm{OPC}+4 \% \mathrm{TiC})$

Figure 22: Effect of (4\% $\mathrm{SiC})$ and $(4 \% \mathrm{TiC})$ nanoparticles on the water absorption for the cement paste specimens at different curing time.

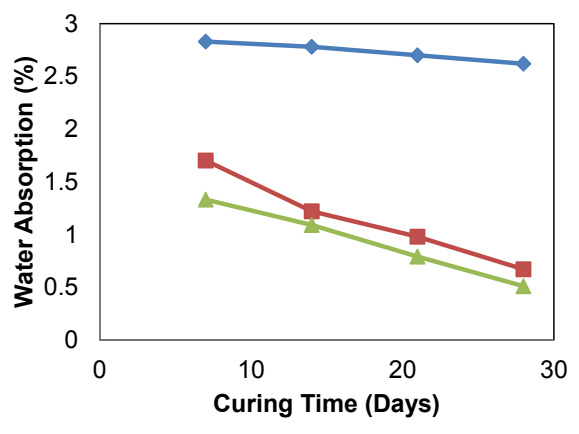

$\leadsto \mathrm{OPC}-(\mathrm{OPC}+5 \% \mathrm{SiC}) \leadsto(\mathrm{OPC}+5 \% \mathrm{TiC})$

Figure 23: Effect of ( $5 \% \mathrm{SiC})$ and $(5 \% \mathrm{TiC})$ nanoparticles on the water absorption for the cement paste specimens at different curing time.

with increasing curing time and the nanoparticles percentages up to $(5 \%)$. The lowest water absorption of cement paste samples was associated with $5 \% \mathrm{TiC}$ and $5 \% \mathrm{SiC}$ at curing time 28 days. The nanoparticles have generally decreased the total water absorption particularly in the case of using ( $\mathrm{TiC}$ ) nanoparticles which substantially reduced the water absorption. This may be due to "the higher fineness of nanoparticles that led to fill the pores spaces and to disconnect the continuity of the capillary pores" [24].

The testing results also indicated that the absorption of the cement pastes modified by nanoparticles continuously decreased with 


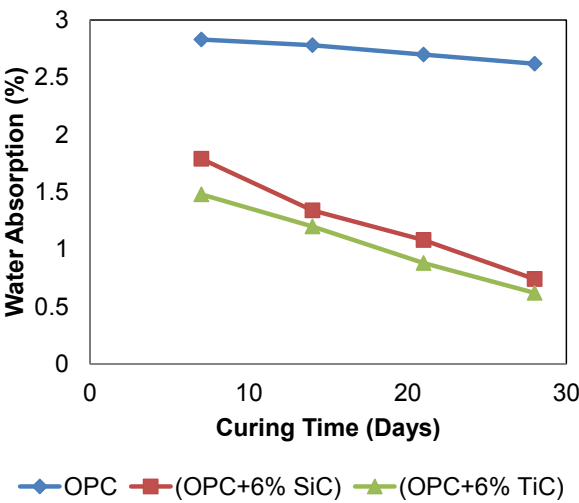

Figure 24: Effect of $(6 \% \mathrm{SiC})$ and $(6 \% \mathrm{TiC})$ nanoparticles on the water absorption for the cement paste specimens at different curing time.

increasing of the nanoparticles. This is because the partial filling of the cement pastes pores by the hydration by products, which reduce the capillary porosity [24]. The decreasing in water absorption may also be due to the enhancement of the cement paste porosity by both the physical and the chemical mechanisms of the nanoparticles. The nanoparticles can make the pore structure of cement paste more homogeneous by decreasing the number of large pores [26]. However, the absence of the nanoparticles can lead to "growing large crystals of $\mathrm{CH}$ that tend to be parallel to aggregate particles surface" [24]. The $\mathrm{CH}$ crystals cannot contribute to the strength of cement pastes due to the $\mathrm{CH}$ crystals can be easily cleaved [24,28].

\section{Scanning Electron Microscopy (SEM)}

The analysis of structural, quality and morphology of ( $\mathrm{SiC}$ and $\mathrm{TiC})$ nanoparticles can be identified by SEM. The SEM images shown in Figures 25 and 26 illustrate the morphology and the distribution of $\mathrm{SiC}$ and $\mathrm{TiC}$ nanoparticle materials, respectively. It can be seen from these figures that some of $\mathrm{SiC}$ and $\mathrm{TiC}$ particulates have fused together. It is also shown in Figures 25 and 26 that $\mathrm{SiC}$ and $\mathrm{TiC}$ nanoparticles had various particle structures including spherical particles and irregular shape particles, as well as agglomerated and rounded particles. The tendency for agglomeration of particles may be related to Van-derWaal forces that act between the individual particles (data not shown).

Figure 27 shows the SEM micrograph of the control cement paste mixture at the curing time of 28 days. It can be noticed from Figure 27 that the control cement pastes mixture had a porous structure that contained a full of large size pores and the presence of $\mathrm{Ca}(\mathrm{OH})$. The existence of many $\mathrm{CH}$ crystals connected to the C-S-H gel indicated that the hydration process was not completed which explained the reduction of mechanical properties for the control cement pastes mixtures. It is also depicted from Fig. 27 that the concentration of the $\mathrm{CH}$ was higher than the $\mathrm{C}-\mathrm{S}-\mathrm{H}$ gel concentration, and the $\mathrm{CH}$ hydrate needles covered a large area in the control cement pastes specimens [29].

Figures 28 and 29 show SEM of the cement pastes samples with (5\% $\mathrm{SiC}$ and $5 \% \mathrm{TiC}$ ) nanoparticles, respectively at curing time 28 days that resulted in the highest mechanical properties than the other specimens having different nanoparticles percentages. These Figures show that the cement pastes with ( $\mathrm{SiC}$ and $\mathrm{TiC}$ ) nanoparticles samples had lower densities, and were more uniform than the control cement pastes specimens. They also had a small number of $\mathrm{Ca}(\mathrm{OH})_{2}$ crystals and small sized pores. It can also be noted from Figures 28 and 29 that the $\mathrm{CH}$ needles were invisible, and there was a compact structure with the absence of the un-hydrated crystals and voids. It is also shown

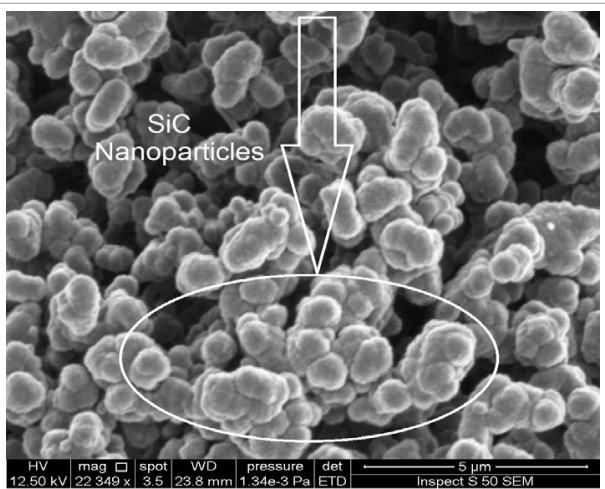

Figure 25: SEM image of (SiC) nanoparticles.

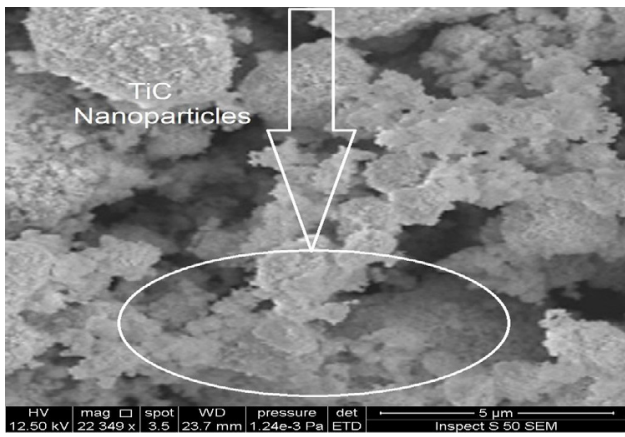

Figure 26: SEM image of (TiC) nanoparticles.

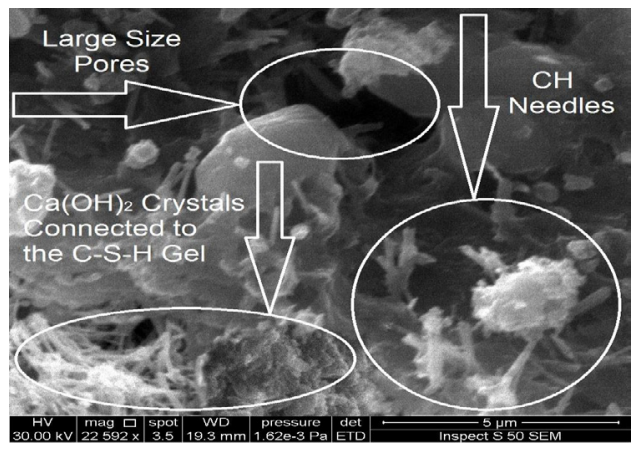

Figure 27: SEM image of the cement paste without nanoparticles at curing time 28 days.

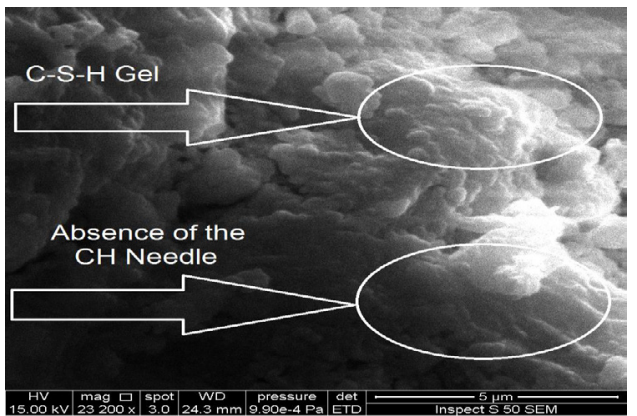

Figure 28: SEM image of cement paste with $(5 \% \mathrm{SiC})$ nanoparticles at curing time 28 days.

from these figures that the cement pastes specimens with nanoparticles were more uniform and homogeneous than the control cement paste specimens. This could interpret the improvements of mechanical 
Citation: Mahawish A, Ibrahim SI, Jawad AH, Othman FM (2017) Effect of Adding Silicon Carbide and Titanium Carbide Nanoparticles on the Performance of the Cement Pastes. J Civil Environ Eng 7: 277. doi: 10.4172/2165-784X.1000277

Page 8 of 10

properties (flexural strength, splitting tensile strength and Compressive strength). The improvements of mechanical properties may be related to the high activity of many nanoparticles. The nanomaterial can consume "calcium hydroxide crystals, fill pores to increase the strength, reduce the size of the crystals at the interface zone, transmute the calcium hydroxide feeble crystals to the C-S-H crystals, and improve the interface zone and the cement paste structures" [29,30].

\section{Energy Dispersive X-ray Spectroscopy (EDS)}

EDS composition analyses of the $(\mathrm{SiC})$ nanoparticles are shown in Figure 30 and Table 3 The compositions mainly consisted of silicon and carbon, whereas Figure 31 and Table 4 show EDS compositions of (TiC) nanoparticles. The compositions mainly contained titanium and carbon. The EDX composition analysis for the control cement paste sample is shown in Figure 32 and Table 5. Figure 32 reveals that the compositions of the cement paste comprised of carbon, oxygen, silicon, and calcium.

Figures 33 and 34 and Tables 6 and 7 present EDX of the cement pastes modified by ( $5 \% \mathrm{SiC}$ and $5 \% \mathrm{TiC}$ ) nanoparticles, respectively. The main reason for conducting EDX on these samples was because using (5\% $\mathrm{SiC}$ and $5 \% \mathrm{TiC}$ ) resulted in the highest mechanical properties at a curing time 28 days than other specimens having different nanoparticles percentages. It can be seen from Figures 33 and 34 that the chemical compositions of the samples mainly contained carbon, oxygen, silicon, calcium, and nanoparticles. EDS analyses showed that the cement paste samples with nanoparticles had a more uniform distribution and a higher concentration of nanoparticles than the control cement pastes [31].

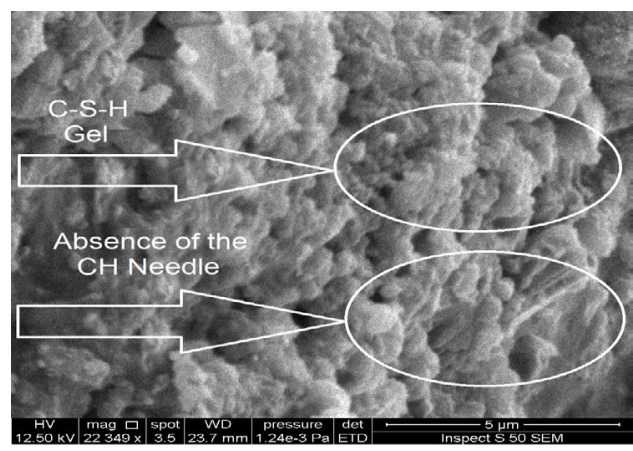

Figure 29: SEM image of cement paste with ( $5 \% \mathrm{TiC})$ nanoparticles at curing time 28 days.

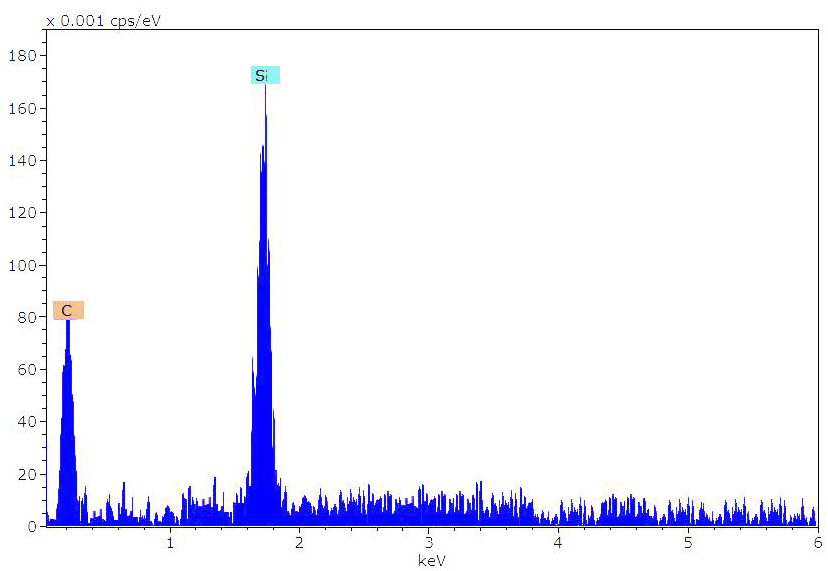

Figure 30: EDS analysis of ( $\mathrm{SiC})$ nanoparticles.

\begin{tabular}{|c|c|c|}
\hline Element & Weight $\%$ & Atomic $\%$ \\
\hline $\mathrm{C}$ & 27.58 & 46.68 \\
\hline $\mathrm{Si}$ & 72.42 & 53.32 \\
\hline Totals & 100 & 100 \\
\hline
\end{tabular}

Table 3: EDS results of $\mathrm{SiC}$ nanoparticles.

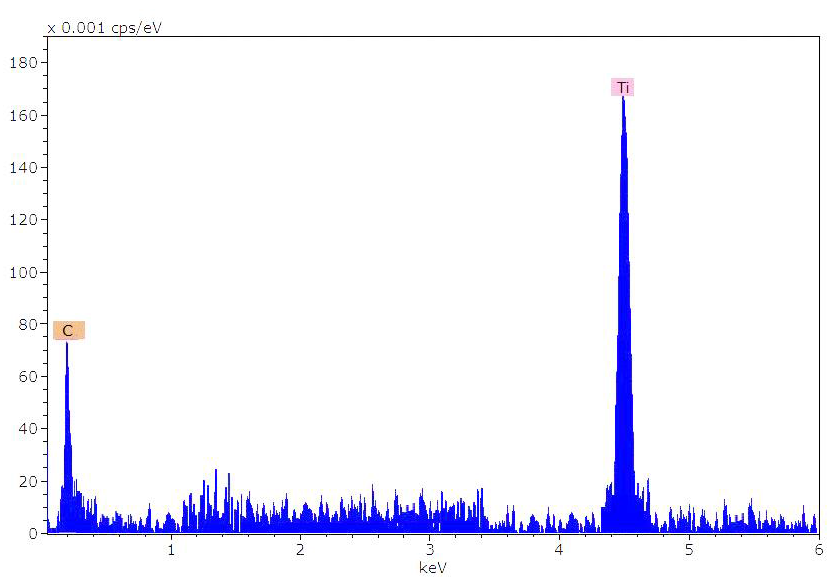

Figure 31: EDS analysis of $(\mathrm{TiC})$ nanoparticles.

\begin{tabular}{|c|c|c|}
\hline Element & Weight $\%$ & Atomic $\%$ \\
\hline $\mathrm{C}$ & 26.62 & 45.05 \\
\hline $\mathrm{Si}$ & 73.42 & 54.95 \\
\hline Totals & 100 & 100 \\
\hline
\end{tabular}

Table 4: EDS results of TiC nanoparticles.

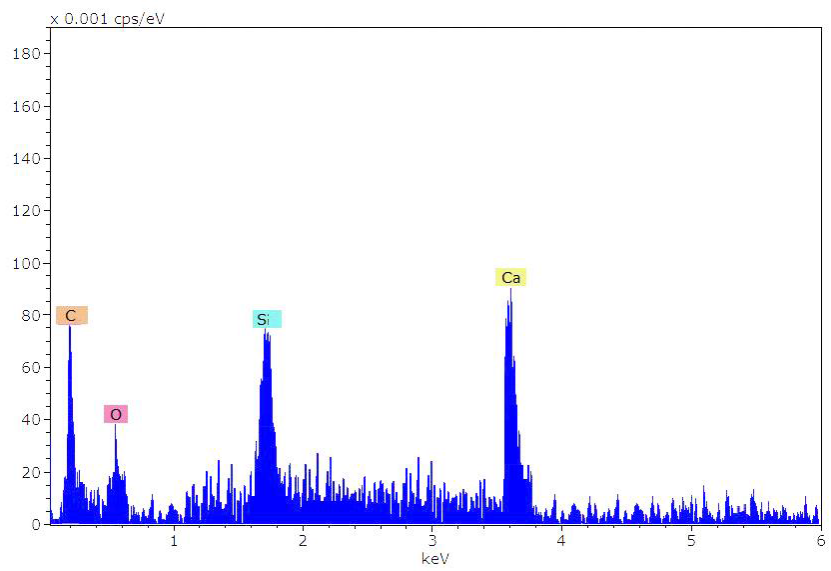

Figure 32: EDS analysis of cement paste without nanoparticles at curing time 28 days.

\begin{tabular}{|c|c|c|}
\hline Element & Weight $\%$ & Atomic $\%$ \\
\hline $\mathrm{C}$ & 26.81 & 45.65 \\
\hline $\mathrm{O}$ & 14.64 & 18.72 \\
\hline $\mathrm{Si}$ & 26.53 & 19.3 \\
\hline $\mathrm{Ca}$ & 32.02 & 16.33 \\
\hline Total & 100 & 100 \\
\hline
\end{tabular}

Table 5: EDS results of the cement pastes.

\section{Conclusion}

In recent years, different types of nanoparticles have been used in Portland cement in order to improve the pore structure of cement 


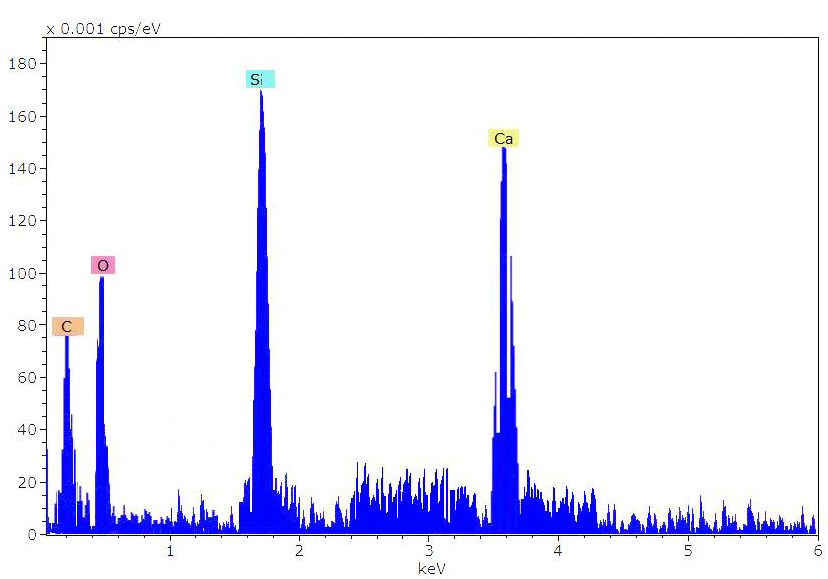

Figure 33: EDS analysis of cement paste with $(5 \% \mathrm{SiC})$ nanoparticles at curing time, 28 days.

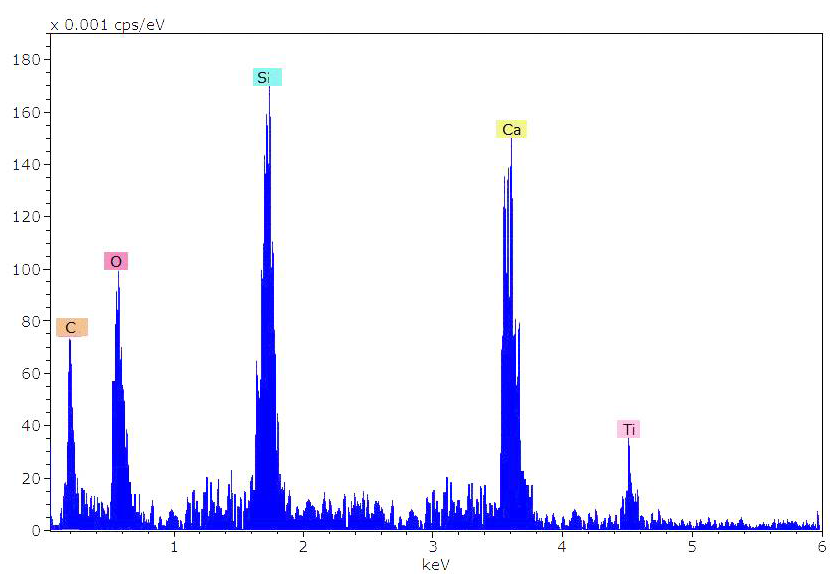

Figure 34: EDS analysis of cement paste with $(5 \% \mathrm{TiC})$ nanoparticles at curing time, 28 days.

\begin{tabular}{|c|c|c|}
\hline Element & Weight $\%$ & Atomic $\%$ \\
\hline $\mathrm{C}$ & 17.73 & 31.61 \\
\hline $\mathrm{O}$ & 20.95 & 27.97 \\
\hline $\mathrm{Si}$ & 33.69 & 25.59 \\
\hline $\mathrm{Ca}$ & 27.63 & 14.83 \\
\hline Total & 100 & 100 \\
\hline
\end{tabular}

Table 6: EDS results of $\mathrm{SiC}$ nanoparticles modified the cement pastes.

\begin{tabular}{|c|c|c|}
\hline Element & Weight $\%$ & Atomic $\%$ \\
\hline $\mathrm{C}$ & 16.07 & 29.24 \\
\hline $\mathrm{O}$ & 21.31 & 29.23 \\
\hline $\mathrm{Si}$ & 33.03 & 25.72 \\
\hline $\mathrm{Ca}$ & 28.66 & 15.6 \\
\hline $\mathrm{Ti}$ & 0.93 & 0.21 \\
\hline Total & 100 & 100 \\
\hline
\end{tabular}

Table 7: EDS results of TiC nanoparticles modified the cement pastes.

pastes. Most research has studied the use of $\mathrm{SiO}_{2}$ nanoparticles. Few studies have incorporated other nanoparticles in cement pastes. In the present study, the influence of ( $\mathrm{SiC}$ and $\mathrm{TiC}$ ) nanoparticles on compressive strength, splitting tensile strength, flexural strength and water absorption of cement paste was investigated.

The results obtained can be summarized as follows:
1. Adding nanoparticles has improved the mechanical properties such the compressive strength, the splitting tensile strength and the flexural strength and the maximum values of the mechanical properties were associated with the cement pastes modified by $(5 \%$ $\mathrm{TiC})$ and $(5 \% \mathrm{SiC})$ nanoparticles at a curing time 28 days.

2. The physical properties such as water absorption has enhanced by adding the nanoparticles, where the water absorption was substantially reduced. The lowest water absorption obtained from the samples modified with $(5 \% \mathrm{TiC})$ and $(5 \% \mathrm{SiC})$ nanoparticles at curing time 28 days.

3. SEM and EDS results indicate that the addition of nanoparticles led to a significant consume of Portlandite $(\mathrm{CH})$ in the pozzolanic reaction, and resulted in a significant reduction of voids and gaps.

4. Increasing the percentages of nanoparticles up to (5\%) of ( $\mathrm{SiC}$ and $\mathrm{TiC}$ ) enhanced the mechanical and physical properties. However, an adverse trend was detected when the percentage of ( $\mathrm{SiC}$ and $\mathrm{TiC}$ ) nanoparticles was increased to (6\%) leading to slumped properties.

5. The (mechanical and physical) properties were improved with increasing the curing time $(7,14,21$, and 28 days).

6. The results revealed that the cement pastes treated by $(\mathrm{TiC})$ nanoparticles had higher mechanical and physical properties than (SiC) nanoparticles.

\section{Acknowledgments}

The authors acknowledge the support provided by the department of building and construction engineering of university of technology, Baghdad and the SEM center at university of technology.

\section{References}

1. Sobolev K, Flores I, Hermosillo R, Torres-Martínez LM (2006) Nanomaterials and nanotechnology for high-performance cement composites, Proceedings of $\mathrm{ACl}$ Session on Nanotechnology of concrete: Recent developments and future perspectives, Denver, USA.

2. Sanchez F, Sobolev K (2010) Nanotechnology in concrete - A review. Constr Build Mater. 24: 2060-71.

3. Nazari A, Riahi S (2011) $\mathrm{TiO}_{2}$ nanoparticles effects on physical, thermal and mechanical properties of self compacting concrete with ground granulated blast furnace slag as binder. Energ Buildings 43: 995-1002.

4. Zhang MH, Li H (2011) Pore structure and chloride permeability of concrete containing nano-particles for pavement. Constr Build Mater 25: 608-616.

5. Chen J, Kou SC, Poon CS (2012). Hydration and properties of nano-TiO blended cement composites. Cement and Concrete Composites 34: 642-649.

6. Diamond S (1986) Concrete structure, properties and materials. Cement Concrete Res 16:790

7. Collepardi M, Collepardi S, Skarp U, Troli R (2004) Optimization of silica fume, fly ash and amorphous nano-silica in super plasticized high-performance concretes. Proceedings of 8th CANMET/ACI International Conference on Fly Ash, Silica Fume, Slag and Natural Pozzolans in Concrete, SP-221.

8. Li H, Xiao HG, Yuan J, Ou J (2004) Microstructure of cement mortar with nanoparticles. Composites Part B 35:185-189.

9. Jo BW, Kim CH, Tae GH, Park JB (2007) Characteristics of cement mortar with nano-SiO 2 particles. Constr Build Mater 21:1351-1355.

10. Senff L, Hotza D, Repette WL, Ferreira VM, Labrincha JA (2010) Mortars with nano- $\mathrm{SiO}_{2}$ and micro-SiO ${ }_{2}$ investigated by experimental design. Constr Build Mater 24:1432-1437.

11. Qing Y, Zenan Z, Li S, Rongshen C (2006) A comparative study on the pozzolanic activity between nano-SiO ${ }_{2}$ and silica fume. Journal of Wuhan University of Technology. Mater Sci Ed 21:153-157.

12. Ulm FJ, Vandamme M (2009) Probing Nano-structure of C-S-H by Micro- 
Citation: Mahawish A, Ibrahim SI, Jawad AH, Othman FM (2017) Effect of Adding Silicon Carbide and Titanium Carbide Nanoparticles on the Performance of the Cement Pastes. J Civil Environ Eng 7: 277. doi: 10.4172/2165-784X.1000277

mechanics Based Indentation Techniques. Nanotechnology in Construction 3: 43-53.

13. Zyganitidis I, Stefanidou M, Kalfagiannis N, Logothetidis (2011) Nanomechanical characterization of cement-based pastes enriched with $\mathrm{SiO}_{2}$ nanoparticles. Mater Sci Eng B. 176: 1580-1584.

14. Corr D, Shah SP (2005) Concrete materials science at the Nano scale. Applications of Nanotechnology in Concrete Design 2-12.

15. Quercia G, Brouwers HJH (2010) Application of nano-silica (nS) in concrete mixtures. $8^{\text {th }}$ fib International Ph. D. Symposium in Civil Engineering. Lyngby

16. Porro A, Dolado JS, Campillo I, Erkizia E, De Miguel Y, et al. (2005) Effects of nano silica additions on cement pastes. Applications of Nanotechnology in Concrete Design 2: 87-96.

17. Metaxa Z, Konsta-Gdoutos MS, Shah SP (2009). Carbon nanotubes reinforced concrete. Special Publication 267: 11-20.

18. Lee BY, Kurtis KE (2010) Influence of $\mathrm{TiO}_{2}$ nanoparticles on early C3S hydration. J Am Ceram Soc 93: 3399-3405.

19. Sobolev K, Gutiérrez MF (2005) How nanotechnology can change the concrete world. American Ceramic Society Bulletin. 84:14-18.

20. Sobolev K, Flores I, Torres-Martinez L, Valdez P, Zarazua E, et al. (2009) Engineering of $\mathrm{SiO}_{2}$ nanoparticles for optimal performance in nano cementbased materials. Nanotechnology in Construction 3:139-148.

21. Said AM, Zeidan MS (2009) Enhancing the reactivity of normal and fly ash concrete using colloidal nano-silica. Special Publication 267: 75-86.
22. Hosseini $P$, Booshehrian $A$, Farshchi $S$ (2010) Influence of nano-SiO ${ }_{2}$ addition on microstructure and mechanical properties of cement mortars for ferrocement. Transp Res Rec 2141: 15-20.

23. Haruehansapong S, Pulngern T, Chucheepsakul S (2014) Effect of the particle size of nanosilica on the compressive strength and the optimum replacement content of cement mortar containing nano- $\mathrm{SiO}_{2}$. Constr Build Mater 50: 471-477.

24. Jahren $P$ (1983) Use of silica fume in concrete International Concrete Abstracts Portal, Special Publication 79: 625-642.

25. Gjørv OE, Sakai K, Banthia N (1998) Concrete under severe conditions 2 Environment and loading: Proceedings of the Second International Conference on concrete under severe conditions, CONSEC'98, Norway, CRC Press, USA

26. Lee SJ, Kriven WM (2005). Synthesis and hydration study of Portland cement components prepared by the organic steric entrapment method. Mater Struct 38: $87-92$.

27. Li H, Zhang MH, Ou JP (2007) Flexural fatigue performance of concrete containing nano-particles for pavement. Int J Fatigue 29: 1292-1301.

28. Neville AM (1995) Properties of concrete (5th edn), Pearson Education Limited, Edinburgh-Harlow, England.

29. Quercia G, Spiesz P, Hüsken G, Brouwers HJH (2014) SCC modification by use of amorphous nano-silica. Cem Concr Compos 45: 69-81.

30. Shah VS (2004) Detection of microcracks in concrete cured at elevated temperature. PhD dissertation, University of Florida, USA.

31. $\mathrm{Li} \mathrm{G} \mathrm{(2004)} \mathrm{Properties} \mathrm{of} \mathrm{high-volume} \mathrm{fly} \mathrm{ash} \mathrm{concrete} \mathrm{incorporating} \mathrm{nano-SiO}$ Cem Concr Res 34: 1043-1049. 